\title{
PemanfaAtan Sarang Semut (Mrrmecodia SP.) Asal Sasnek - Wendi Kabupaten Sorong Selatan SEbagai Teh Sarang Semut
}

\author{
UTILIZATION OF ANT-PLANT (MYRMECODIA SP.) \\ FROM SASNEK - WENDI, SOUTH SORONG REGENCY \\ AS AN ANT-PLANT
}

\author{
Reynold Kesaulija ${ }^{1, *}$, Yohanis R. P. Harsono ${ }^{2}$, Salomi Rijoly \\ 1,2, ${ }^{3}$ Kesatuan Pengelolaan Hutan Produksi Sorong Selatan Unit V \\ Wayer-Sorong Selatan, Papua Barat
}

Dikirim: 13 Januari 2020; Disetujui: 28 Mei 2020; Diterbitkan: 29 Juni 2020

\begin{abstract}
Inti Sari
Potensi KPHP Sorong Selatan Unit V baik berupa hasil kayu, non kayu dan jasa cukup melimpah. Salah satu potensi adalah komoditi sarang semut yang perlu dikelola secara berkelanjutan agar memberikan manfaat bagi masyarakat dan pembangunan daerah. KPHP melibatkan masyarakat untuk meningkatkan nilai tambah sarang semut melalui inovasi pengelolaan menghasilkan produk teh sarang semut. Berdasarkan hasil kajian menemukan bahwa proses pembuatan teh sarang semut terbagi dalam 3 tahapan yaitu penyiapan sarang semut, pengeringan sarang semut, pembuatan serbuk menjadi produk teh kemasan. Introduksi teknologi tepat guna dalam pemanfaatan tumbuhan sarang semut menjadi produk teh celup sarang semut dengan nama produk Sarmut SW.
\end{abstract}

Kata Kunci: Sarang Semut, Teh, KPHP, Sorong Selatan.

\begin{abstract}
Environmental services, timber and non-timber forest products are abundant in KPHP Sorong Selatan. Antplant (Myrmecodia sp.) is one of the non-timber forest products which is has great potential usages and must be managed to gain benefits for the locals and the development of the Sorong Selatan regency. KPHP has been involving local community to improve ant-plant as an innovative product. This paper examined the potential of ant plant within KPHP Sorong Selatan and the tea producing processes. The result indicated ant-pant has great potential, what need is and introduction of technology in the process of making tea that includes packaging.
\end{abstract}

Keywords: Ant-plant (Myrmecodia sp.), tea, KPHP, South Sorong.

* Korespondensi Penulis Telepon : +62 82199632107

Email : kesaulijareynold@gmail.com 


\section{Pendahuluan}

Hutan merupakan salah satu sumber daya alam dan menjadi penyanggah kehidupan yang keberadaannya tidak tergantikan karena dapat memberi manfaat dalam bentuk barang dan atau jasa secara ekologi, ekonomi dan sosial secara terus menerus dengan tidak menimbulkan dampak negatif. Untuk itu diperlukan sistem pengelolaan dan institusi/ kelembagaan pengelolaan hutan di tingkat tapak yang andal dan profesional sehingga sumber daya hutan dapat memberikan manfaat sesuai dengan fungsinya, khususnya melalui unit Pengelolaan Hutan atau Kesatuan Pengelolaan Hutan (KPH). Dengan demikian dalam konteks pengelolaan hutan lestari, keberadaan KPH akan menjamin keberhasilan kelola sosial, kelola lingkungan dan kelola ekonomi (Djajono, 2018).

KPHP Sorong Selatan Unit V dengan luasan \pm 283.260 hektar berada di Provinsi Papua Barat yang melingkupi 3 wilayah administrasi Kabupaten yaitu, Kabupaten Sorong Selatan, Kabupaten Maybrat dan Kabupaten Sorong (Keputusan Menteri Kehutanan Nomor: SK Menhut 771/Menhut-VII/2012) memiliki potensi sumber daya hutan, baik kayu, non kayu dan jasa lingkungan. Salah satu dari sekian potensi hasil hutan bukan kayu (HHBK) unggulan di KPHP Sorong Selatan Unit V di antaranya yaitu komoditi sarang semut yang perlu dikelola secara berkelanjutan agar memberikan manfaat bagi masyarakat dan pembangunan daerah.

Sarang semut merupakan tumbuhan dari famili Rubiaceae yang bersifat epifit, artinya tumbuhan yang menempel pada tumbuhan lain tetapi tidak hidup secara parasit pada inangnya dan berasosiasi dengan semut. Bagian luar tumbuhan ini diselubungi duri yang melindunginya dari pemangsa herbivor, yang menarik di dalamnya terdapat rongga-rongga yang saling terhubung. Rongga-rongga ini dijadikan rumah oleh kawanan semut sehingga tumbuhan ini lazim disebut sarang semut. Secara tradisi, sarang semut digunakan sebagai tumbuhan obat oleh masyarakat pedalaman di bagian barat Wamena, Papua. Suku-suku di Bogondini dan Tolikara lazim memanfaatkannya untuk mengatasi rematik dan asam urat (Crisnaningtyas \& Rachmadi, 2010).

Secara etnofarmakologi tumbuhan sarang semut telah digunakan sebagai obat oleh masyarakat pedalaman Papua, di antaranya penyembuh radang, menguatkan imunitas tubuh dan mengatasi nyeri otot. Salah satu khasiat utamanya adalah membantu pengobatan berbagai jenis tumor dan kanker seperti : kanker otak, kanker payudara, kanker hidung, kanker liver, kanker paru-paru, kanker usus, kanker rahim, kanker kulit, kanker prostat dan leukemia (Mardany et al., 2016). Berdasarkan beberapa hasil penelitian manfaat sarang semut untuk kesehatan antara lain sebagai antioksidan dan antimikroba serta efektif dalam membantu penyembuhan berbagai macam penyakit lainnya, misalnya gangguan jantung, ambeien (wasir), reumatik, stroke ringan maupun berat, maag, gangguan fungsi ginjal dan prostat, pegal linu, melancarkan dan meningkatkan jumlah Air Susu Ibu (ASI), melancarkan peredaran darah, dan memulihkan gairah seksual (Sudiono et al., 2015). Salah satu upaya untuk memberikan nilai tambah dari tumbuhan sarang semut yang pengolahannya, yaitu memanfaatkan serbuk umbi tumbuhan sarang semut sebagai minuman seduhan yaitu teh.

Berdasarkan deskripsi dan informasi keunggulan utama sarang semut di atas maka menjadi tantangan tersendiri bagi KPH yang ada di Papua bagaimana upaya untuk memberikan nilai tambah dalam sistem pengelolaan yang lebih adaptif dan bernilai ekonomi tinggi. Paper ini bertujuan untuk mendeskripsikan proses pemanfaatan sarang semut (Myrmecodia sp.) sebagai teh sarang semut pada wilayah KPHP Sorong Selatan Unit $\mathrm{V}$ dalam menjawab tantangan tersebut. 


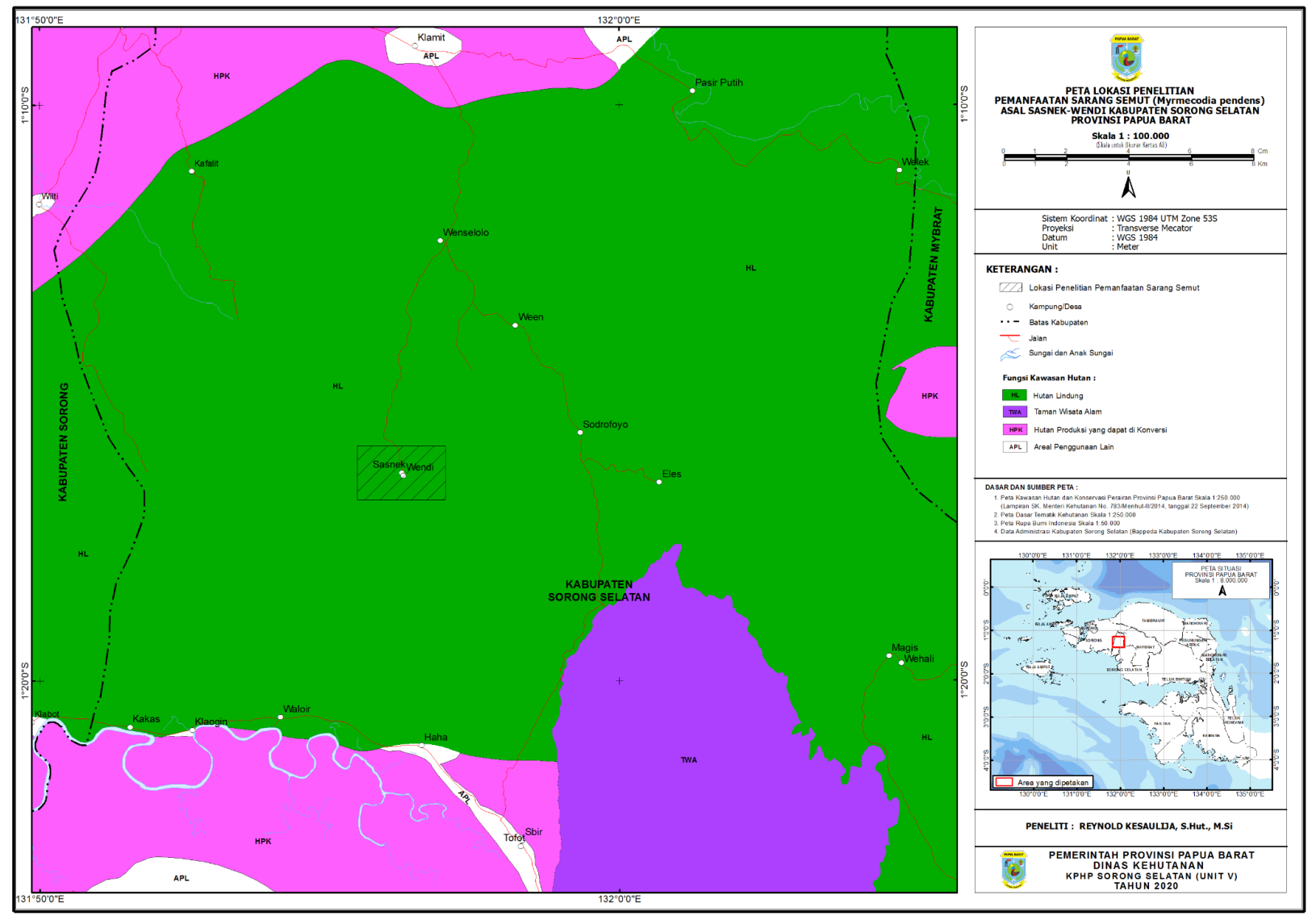

Gambar 1. Peta Lokasi Penelitian

\section{Metode}

\section{A. Tempat dan Waktu}

Penelitian ini dilaksanakan di Kampung Wendi dan Sasnek, Distrik Sawiat yang berada pada areal KPHP Sorong Selatan Unit V dan Koperasi Wanalestari. Peta lokasi penelitian disajikan pada Gambar 1. Waktu penelitian secara keseluruhan berlangsung selama satu bulan yaitu dari tanggal 31 Juli sampai 30 Agustus 2019.

\section{B. Bahan dan Alat Penelitian}

Bahan digunakan dalam penelitian ini adalah umbi sarang semut yang telah tua dan matang, air bersih dan kantong teh. Peralatan yang digunakan di antaranya adalah pisau, nampan, loyang, sendok, ayakan ukuran 60 mesh, blender, plastik kemasan, timbangan digital, mesin press serta peralatan wawancara.

\section{Metode Penelitian}

Penelitian ini menggunakan metode kualitatif deskriptif dengan teknik pendekatan studi kasus (case study). Dalam pengumpulan data digunakan teknik observasi, wawancara dengan alat bantu kuesioner, studi pustaka/ literatur dan dokumentasi. Pemilihan kampung/desa sebagai lokasi penelitian dilakukan secara sengaja (purposive sampling) di mana kampung yang dipilih merupakan kampung penghasil sarang semut dan telah melakukan pengolahan dan pemanfaatan sarang semut. Data yang dikumpulkan dalam penelitian ini terdiri dari data sekunder dan data primer. Data sekunder dikumpulkan melalui studi literatur dan studi dokumentasi dari berbagai buku dan jurnal yang berhubungan dengan tujuan penelitian. Data primer didapatkan melalui wawancara mendalam (in-depth interview), pengamatan 
langsung di lokasi penelitian (observation), diskusi kelompok terarah/Focus Group Discussion (FGD) dan survei.

\section{Pelaksanaan Penelitian}

Melakukan observasi pada proses pemanenan tumbuhan sarang semut, pengolahan umbi sarang semut dari tahapan umbi ditimbang, kulit luar umbi dikupas dan umbi dibelah menjadi beberapa bagian, kemudian umbi tersebut dibersihkan dari kotoran dan semut yang berada di dalamnya. Belahan umbi tersebut diiris dan dikering anginkan atau dijemur di bawah sinar matahari selama 5-6 hari sehingga diperoleh irisan sarang semut kering dengan kadar air 7\%. Pembuatan serbuk sarang semut menggunakan bahan dari irisan sarang semut kering dengan cara irisan dihaluskan dengan menggunakan blender kering kemudian diayak dengan ukuran 70 mesh sehingga diperoleh serbuk sarang semut kemudian dimasukkan ke dalam kantong teh celup dan disealer serta dimasukkan di dalam kemasan sekunder. Selanjutnya melakukan wawancara dan FGD kepada pengurus kelompok tani hutan dan pengurus Koperasi Wanalestari serta melakukan survei harga teh herbal di pasaran.

\section{Hasil dan Pembahasan}

\section{A. Deskripsi Sarang Semut}

Myrmecodia berasal dari kata myrmikodes yang berasal dari bahasa Yunani yang berarti mirip semut atau dikerumuni semut (Wulan et al., 2017). Sarang semut merupakan salah satu tumbuhan epifit dari Hydnophytinae (Rubiaceae) yang dapat bersimbiosis dengan semut dan dikatakan bersifat epifit karena tumbuhan ini menempel pada tumbuhan lain tetapi tidak hidup secara parasit pada inangnya sehingga hanya sebagai tempat menempel saja. Tumbuhan sarang semut memiliki kekhasan, yakni ujung batangnya menggelembung (hypocotyl), berbentuk bulat saat muda, lalu menjadi lonjong memendek atau memanjang
Tabel 1.

Klasifikasi Myrmecodia pendans

\begin{tabular}{ll} 
& \multicolumn{1}{c}{ Kingdom } \\
Divisi & Tracheophyta \\
\hline Kelas & Magnoliopsida \\
\hline Sub kelas & Lamiidae \\
\hline Ordo & Rubiales \\
\hline Famili & Rubiaceae \\
\hline Genus & Myrmecodia \\
\hline Spesies & Myrmecodia pendans \\
\hline Sumber: Wulan etal. (2017) &
\end{tabular}

setelah tua. Bagian luar tumbuhan ini diselubungi duri yang melindunginya dari pemangsa herbivor, di dalamnya terdapat rongga-rongga yang saling terhubung. dan dijadikan rumah oleh kawanan semut sehingga tumbuhan ini lazim disebut sarang semut (Setiawati \& Crisnaningtyas, 2013).

Sarang semut yang telah lama dikenal dan dimanfaatkan oleh masyarakat sebagai salah satu obat tradisional dan memiliki potensi sebagai antioksidan alami yang mengandung flavonoid, tanin, dan tokoferol (Erminawati \& Naufalin, 2013). Menurut Wabia \& Siburian (2019) tumbuhan sarang semut mampu hidup pada daerah hutan sekunder dan daerah bekas perladangan dengan ketinggian 250 hingga 2.500 meter dari permukaan laut.

\section{B. Proses Pembuatan Sarang Semut}

Aspek penanganan pascapanen merupakan faktor yang sangat penting, pelaksanaan kegiatan pascapanen yang perlu diperhatikan yaitu tempat kerja dan peralatan yang digunakan harus bersih, air yang digunakan harus berkualitas air minum. Ketebalan irisan sarang semut setipis mungkin agar cepat kering (kadar air $\pm 7 \%$ ). Pengeringan sarang semut dilakukan secepat mungkin dan jika pengeringan tertunda maka harus ditempatkan pada tempat yang bersih dan kering, pengemasan sarang semut harus menggunakan jenis kemasan yang tepat agar tidak lembap kembali. Dalam proses 


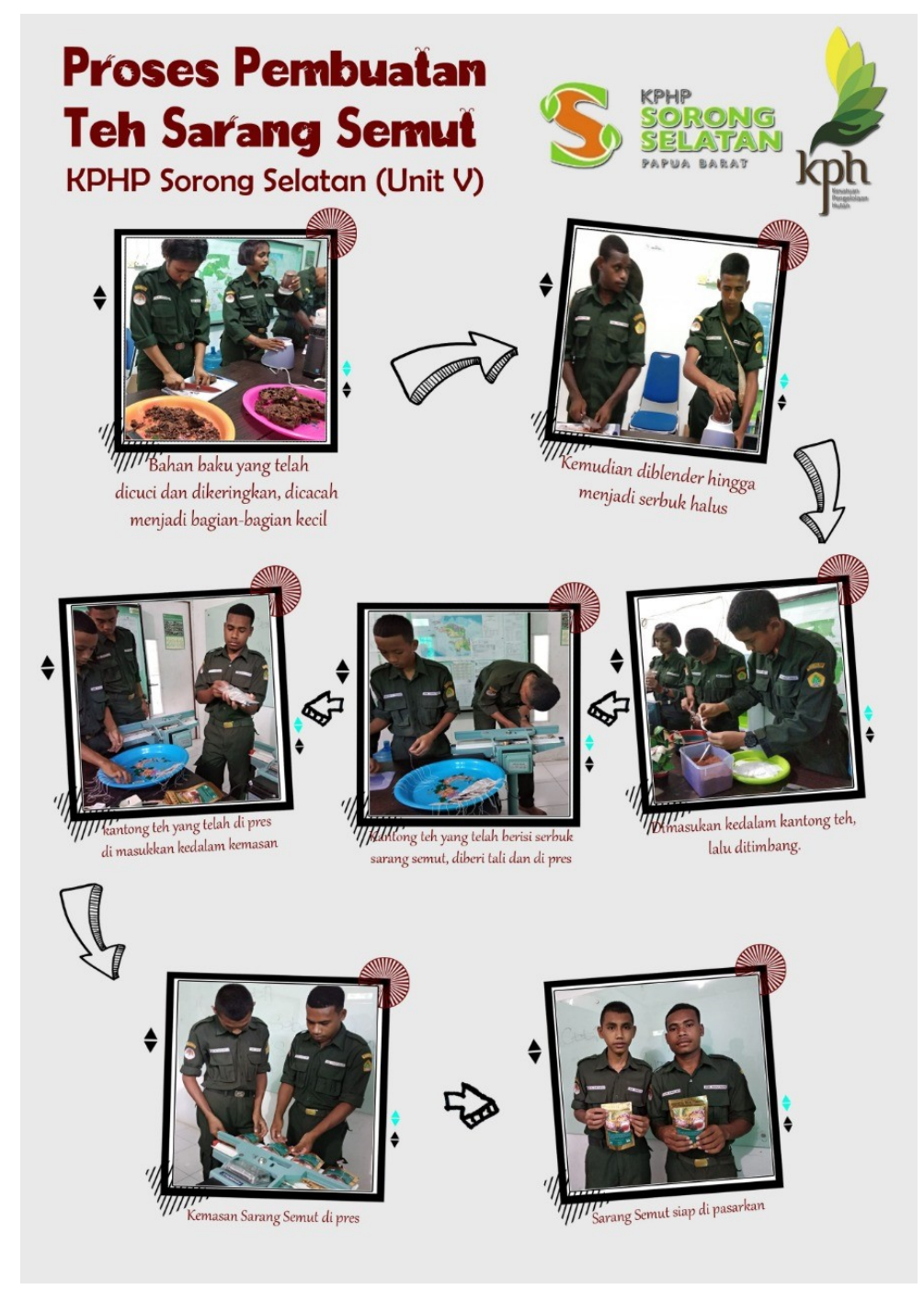

Gambar 2. Proses Pembuatan Teh Sarang Semut

pengolahan atau produksi yang perlu diperhatikan yaitu tempat kerja dan peralatan yang digunakan harus bersih, air yang digunakan harus berkualitas air minum, pengolahan dilakukan dengan tahapan yang benar serta tidak menggunakan/menambah bahan-bahan yang tidak diperbolehkan untuk dikonsumsi.

\section{Pemanfaatan dan Pengelolaan Sarang Semut oleh Masyarakat}

Pemanfaatan sarang semut di Kabupaten Sorong Selatan telah dilakukan oleh masyarakat di Kampung Wendi dan Kampung Sasnek Distrik Sawiat Kabupaten Sorong Selatan. Di mana dalam pengolahan dan pemanfaatannya masih dalam bentuk yang sederhana yaitu masih dalam bentuk bongkahan/lempengan dengan ukuran yang besar yang diproses dengan sederhana dengan pasar yang terbatas. Hal ini mendapat perhatian dari KPHP Sorong Selatan untuk melakukan introduksi teknologi sebagai upaya pengolahan yang lebih higienis dan praktis serta memiliki nilai jual sehingga dapat membantu meningkatkan nilai ekonomi dari sarang semut. Proses pengenalan teknologi kepada masyarakat melalui pelatihan proses pemanenan dan pengolahan sarang semut.

Pengolahan sarang semut yang telah dilakukan oleh masyarakat di Kampung Wendi dan Sasnek secara sederhana yaitu dengan membuat seduhan sarang semut dalam bentuk lempengan/simplisia dari hasil irisan sarang 
semut yang telah dikeringkan. Untuk meningkatkan nilai tambah dari sarang semut maka KPHP Sorong Selatan memperkenalkan dan mengajarkan teknologi sederhana dalam pemanfaatan sarang semut sebagai teh celup sarang semut. Selain itu menerapkan SOP dalam proses pemanenan, pengolahan pasca panen dan proses pengolahan atau produksi teh sarang semut. Kelebihan seduhan sarang semut dalam bentuk teh celup dibandingkan lempengan adalah lebih praktis dan ekonomis dan tidak membutuhkan waktu yang lama untuk menyajikan teh sarang semut. Menurut Dewi \& Dominika (2008) waktu dan suhu penyeduhan tidak menghasilkan perbedaan aktivitas antioksidasi pada serbuk sarang semut.

Pembuatan teh sarang semut yang dibuat dibagi dalam 3 tahapan yaitu penyiapan sarang semut, pengeringan sarang semut, pembuatan serbuk/bubuk sarang semut. Penyiapan sarang semut diawali dengan pemilihan sarang semut yang telah tua/matang kemudian dibuang daun-daun di bagian ujung sarang semut menggunakan pisau kemudian dikupas kulit luar sarang semut memakai pisau atau golok dan buang bagian yang rusak/cacat setelah itu dicuci sarang semut untuk hilangkan kotoran yang menempel, kemudian sarang semut terkupas dibelah 4 bagian, lalu ambil bagian yang berongga saja di mana umbi tersebut harus dibersihkan dari semut yang ada di rongga-rongga. Sarang yang telah dikupas diiris tipis memakai pisau tajam atau mesin pengiris (slicer) setebal $\pm 3 \mathrm{~mm}$. Menurut Erminawati \& Naufalin (2013) hasil analisis ragam menunjukkan bahwa sarang semut dalam bentuk yang berbeda memberikan pengaruh sangat nyata terhadap total fenolik ekstrak sarang semut.

Proses pengeringan dilakukan dengan cara dikeringanginkan dalam ruangan ber-AC pada suhu 25C, sekitar 3 hari, atau dijemur di bawah sinar matahari selama 5-6 hari. Menurut Rivai et al. (2010) pengeringan dengan angin pada suhu $\pm 25 \mathrm{C}$ adalah cara pengeringan yang

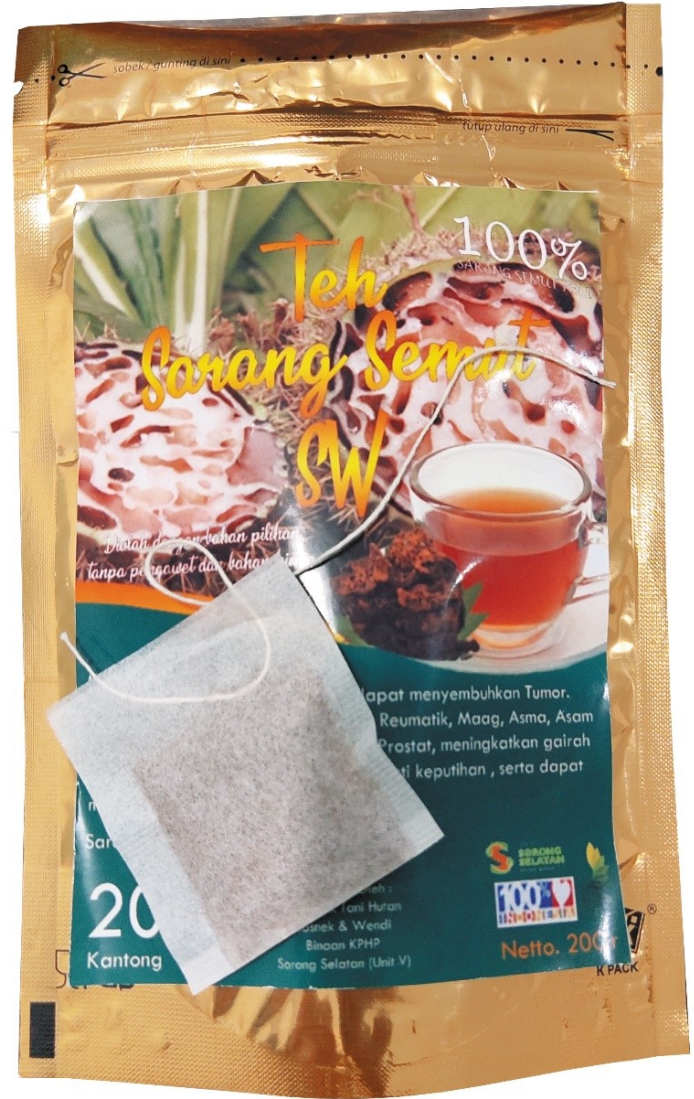

Gambar 3. Teh Celup Sarang Semut (Teh Sarmut SW)

optimum untuk mendapatkan simplisia dengan kadar senyawa fenolat yang tinggi.

Potong-potong sarang semut yang telah kering tersebut menjadi beberapa bagian kecil kemudian diblender sarang semut sampai halus dan dilakukan pengayakan (ukuran 40 60 mesh) setelah dimasukkan ke dalam kantong teh celup kemudian disealer kantong tersebut dan dikemas dalam kemasan sekunder. Sarang semut dalam bentuk bubuk mempunyai nilai total fenolik yang lebih tinggi dibandingkan dengan sarang semut dalam bentuk potongan (Erminawati \& Naufalin, 2013).

Cara membedakan sarang semut asli dan palsu secara sederhana yaitu dengan menggunakan air panas dan melihat tekstur dari sarang semut, jika sarang semut asli diseduh dengan air panas maka airnya masih akan terlihat bening sebaliknya jika airnya berubah menjadi kuning keemasan maka sarang semut tersebut palsu. Apabila dilihat 
dari tekstur maka tekstur dari sarang semut asli terasa agak kasar saat diremas, saat diremas tidak akan mengecil dan masih tetap keras, berbeda dengan sarang semut palsu yang terasa halus dan tipis. Pemanfaatan sarang semut dibuat menjadi kemasan teh celup sarang semut pada Kampung Sasnek dan Wendi dikenal dengan brand teh Sarmut SW (Sasnek-Wendi).

\section{Potensi dan Pemasaran Teh Sarang Semut}

Teh herbal kian popular di kalangan masyarakat karena makin banyak orang yang sadar pentingnya kesehatan. Saat ini banyak bermunculan varian teh herbal di pasaran, salah satu teh herbal yang sedang populer adalah teh herbal sarang semut. Hal ini membuat nilai ekonomi dari sarang semut yang dikemas dalam bentuk teh celup mempunyai nilai yang lebih menjanjikan dibandingkan dengan dijual dalam bentuk lempengan. Sarang semut yang dikemas di dalam kantong teh celup memiliki kelebihan dibanding produk teh celup pada umumnya karena produk ini tidak hanya dapat dikonsumsi oleh penderita penyakit tertentu saja, melainkan dapat juga dikonsumsi oleh semua orang mulai dari anakanak sampai orang dewasa sebagai minuman pelepas dahaga karena rasa dan aroma yang dihasilkan mirip dengan teh pada umumnya.

Secara ekonomi saat ini pemasaran sarang semut masih terbatas pada pasaran lokal dalam bentuk lempengan di Kampung Sasnek dan Kampung Wendi dan pengepul di Kota Sorong.

Tabel 2.

Nilai Produk Sarang Semut

\begin{tabular}{|c|c|c|c|}
\hline No. & Produk & $\begin{array}{l}\text { Harga/kg } \\
\text { (Rp/Kg) }\end{array}$ & Keterangan \\
\hline 1 & $\begin{array}{l}\text { Lempengan/simplisia } \\
\text { kering }\end{array}$ & $\begin{array}{c}35.000,- \text { s.d. } \\
40.000,-\end{array}$ & Pasar lokal \\
\hline 2 & $\begin{array}{l}\text { Lempengan/simplisia } \\
\text { kering }\end{array}$ & $\begin{array}{c}40.000,- \text { s.d. } \\
50.000,-\end{array}$ & $\begin{array}{l}\text { Pasar Kota } \\
\text { Sorong }\end{array}$ \\
\hline 3 & Teh celup Sarmut SW & $625.000,-$ & $\begin{array}{l}20 \mathrm{gr} / \\
\text { kemasan }\end{array}$ \\
\hline
\end{tabular}

Sumber: Data primer (2020)
Tabel 3.

Perbandingan Harga Produk Teh Celup

\begin{tabular}{clc} 
No. & \multicolumn{1}{c}{ Produk } & Harga (Rp) \\
\hline 1 & Teh hitam celup kemasan & 12.000 s.d. 13.000 \\
\hline 2 & $\begin{array}{l}\text { Teh Herbal lainnya (teh daun } \\
\text { kelor) }\end{array}$ & 29.500 s.d. 36.000 \\
\hline 3 & Teh Sarmut SW & 25.000 \\
\hline \multicolumn{2}{l}{ Sumber: Data primer (2020) }
\end{tabular}

Harga sarang semut di pasaran lokal dan kota dapat dilihat pada Tabel 2. Apabila Sarang Semut diolah menjadi teh celup maka dari $1 \mathrm{~kg}$ Sarang semut dapat menjadikan 50 kemasan teh celup sarang semut. Di mana nilai pasar produk dari teh Sarmut SW senilai Rp25.000,-/ kemasan atau Rp1.250.000,- untuk 50 kemasan. Biaya produksi per kg senilai Rp625.000,- sehingga keuntungan yang didapatkan sebesar $100 \%$ atau senilai Rp625.000,-/kg sarang semut.

Terdapat selisih margin harga teh celup sarang semut dengan teh celup kemasan, di mana teh kemasan di pasaran berkisar Rp12.000,- hingga Rp13.000,-/kemasan. Perbandingan harga teh Sarmut SW dengan teh hitam celup dan teh celup herbal lainnya dapat dilihat pada Tabel 3.

Berdasarkan Tabel 2 dapat membandingkan harga 3 produk teh di pasaran. Teh Sarang Semut berada di kisaran pertengahan antara teh hitam celup kemasan dan teh herbal lainnya. Dari perbandingan harga teh celup kemasan dan teh herbal lainnya teh Sarmut SW menjanjikan dalam peningkatan nilai tambah dari pemanfaatan sarang semut.

\section{Kesimpulan}

Berdasarkan hasil kajian dapat disimpulkan bahwa proses pembuatan teh sarang semut yang dibuat dibagi dalam 3 tahapan yaitu penyiapan sarang semut, pengeringan sarang semut, pembuatan serbuk/bubuk sarang semut yang pelibatannya dilakukan oleh masyarakat di Kampung Wendi dan Kampung Sasnek Distrik Wayer Kabupaten 
Sorong Selatan. Nilai tambah ekonomi teh sarang semut sangat menjanjikan karena harganya berkisar di pertengahan harga teh di pasaran. Peran KPH sebagai pembina dalam memberikan introduksi teknologi tepat guna sebagai upaya pengelolaan Hasil Hutan Bukan Kayu (HHBK) dalam pemanfaatan tumbuhan Sarang Semut menjadi teh celup sarang semut (Sarmut SW) yang lebih higienis dan praktis meningkatkan nilai ekonomi dari sarang semut.

\section{Ucapan Terima Kasih}

Penulis mengucapkan terima kasih kepada Kepala Dinas Kehutanan Provinsi Papua Barat yang memberikan kepercayaan kepada kami untuk melaksanakan pengelolaan di KPHP Sorong Selatan dan Kepada Kepala Balai Penelitian dan Pengembangan Daerah Provinsi Papua Barat yang memberikan kesempatan kepada kami. Terima kasih juga kepada para editor anonim yang sudah me-review dan memberikan saran perbaikan naskah tulisan ini.

\section{Referensi}

Crisnaningtyas, F., \& Rachmadi, A. T. (2010). Pemanfaatan Sarang Semut (Myrmecodia pendens) Asal Kalimantan Selatan Sebagai Antibakteri. Jurnal Riset Industri Hasil Hutan, 2(2), 31-35. https://doi.org/ 10.24111/jrihh.v2i2.1144

Dewi, Y. S. K., \& Dominika. (2008). Aktivitas Antioksidasi Ekstrak Fenol Umbi Sarang Semut (Hydnophytum sp.) pada Berbagai Suhu Penyeduhan. Agritech, 28(2), 91-96. https://doi.org/10.22146/agritech.9867

Djajono, A. (2018, March 21). Peran Strategis Kesatuan Pengelolaan Hutan (KPH). Agroindonesia.Co.Id. http:// agroindonesia.co.id/2018/03/peranstrategis-kesatuan-pengelolaan-hutan$\mathrm{kph} /$
Erminawati, \& Naufalin, R. (2013). Sifat Fisikokimia dan Aktivitas Antioksidan Sarang Semut (Myrmecodia pendans) Sebagai Pengawet Alami Pangan. Seminar Nasional PATPI 2013.

Keputusan Menteri Kehutanan Nomor: SK Menhut 771/Menhut-VII/2012 tentang Penetapan Wilayah Kesatuan Pengelolaan Hutan Produksi Model Sorong Selatan (Unit V), yang terletak di Kabupaten Sorong Selatan, Provinsi Papua Barat seluas \pm 283.260 (Dua Ratus Delap, Pub. L. No. 771 (2012).

Mardany, M. P., Chrystomo, L. Y., \& Karim, A. K. (2016). Skrining Fitokimia dan Uji Aktivitas Sitotoksik dari Tumbuhan Sarang Semut (Myrmecodia beccarii Hook. f.) Asal Kabupaten Merauke. Jurnal Biologi Papua, 8(1), 13-22. https://doi.org/10.31957/ jbp.41

Rivai, H., Nurdin, H., Suyani, H., \& Bakhtiar, A. (2010). Pengaruh Cara Pengeringan Terhadap Perolehan Ekstraktif, Kadar Senyawa Fenolat dan Aktivitas Antioksidan dari Daun Dewa (Gynura pseudochina (L.) DC.). Majalah Obat Tradisional, 15(1), 26-33. https://doi.org/ 10.22146/tradmedj.8065

Setiawati, E., \& Crisnaningtyas, F. (2013). Formulasi Permen dari Sarang Semut Asal Kalimantan Selatan. Jurnal Riset Industri Hasil Hutan, 5(2), 31-36. https://doi.org/ 10.24111/jrihh.v5i2.1216

Sudiono, J., Oka, C., \& Trisfilha, P. (2015). The Scientific Base of Myrmecodia pendans as Herbal Remedies. British Journal of Medicine and Medical Research, 8(3), 230237. https://doi.org/10.9734/BJMMR/ 2015/17465

Wabia, E., \& Siburian, R. H. S. (2019). Profil Tempat Tumbuh Sarang Semut (Myrmecodia spp.) di Distrik Manokwari 
Selatan Papua Barat. EnviroScienteae, 15(1), 91-94. https://doi.org/10.20527/ es.v15i1.6328

Wulan, K. N., Muhartono, \& Ramkita, N. (2017).

Sarang Semut (Myrmecodia pendans)
Sebagai Antikanker. Medula, 7(5), 140143. http://juke.kedokteran.unila.ac.id/ index.php/medula/article/view/1922 